\title{
TrafFic Control Through TRAFFIC DENSITY
}

\author{
JAN MRAZEK, LUCIA MRAZKOVA, \\ MARTIN HROMADA \& JAN VAVRA
}

Abstract: The article is focused on dynamic driving in road transport. Current systems on the market are referred to as dynamic but have their limitations. Traffic management is an important aspect to ensure the proper functioning and safety of transport as an element of critical infrastructure. Ensuring the prevention of possible threats can minimize the possibility of threatening other elements of critical infrastructure. The proposed method deals with dynamic driving in road transport. Dynamically controlled traffic lights should ensure greater smoothness, safety and reduce the number of harmful substances emitting vehicles.

Key words: Traffic, Traffic control, Traffic lights, Crisis management, Crisis Situation, Transport, Dynamic control, Clear Air
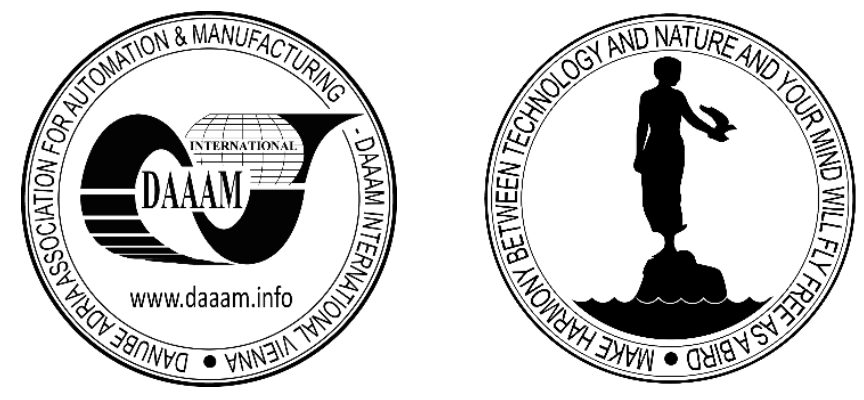

Authors' data: Jan Mrazek, Lucia Mrazkova, Martin Hromada \& Jan Vavra, Tomas Bata University in Zlin, Nad Stranemi 4511, 76005 Zlin, CZ, jmrazek@ utb.cz

This Publication has to be referred as: Mrazek, J[an]; Mrazkova, L[ucia]; Hromada, M[artin] \& Vavra, J[an] (2020). Traffic Control Through Traffic Density, Chapter 22 in DAAAM International Scientific Book 2020, pp.253-258, B. Katalinic (Ed.), Published by DAAAM International, ISBN 978-3-902734-27-3, ISSN 1726-9687, Vienna, Austria

DOI: 10.2507/daaam.scibook.2020.22 
Mrazek, J.; Mrazkova, L.; Hromada, M. \& Vavra, J.: Traffic Control Through Traff...

\section{Introduction}

Heavy traffic is a topical issue worldwide. Most countries are trying to solve this problem their way. There is currently no methodology to suggest traffic management to avoid over-saturation of roads in cities or downtown. All of us know the traffic jams. Over time, we know of places where they are fine and often can not be avoided. However, these situations can occur for several reasons. The main causes are the dense traffic flows flowing into cities for commuting to work or just passing through the city due to the absence of a bypass around the city. [1], [2]

Systems for traffic management in cities are numerous. The current offer on the market shows mostly dynamic systems. These systems should work with real-time data. Like any system has its advantages, these include disadvantages. The current offer on the market is very rich and it can create a smart city in the form of smart cities. The question, however, remains whether it could not be taken one level up. [3]

Our proposed method is one of the methods that is dynamically controlled based on evolving traffic. The method should work with the input data that we get from the transit cameras at the edges of the monitored city. Based on the information we work with and modeling, it should be possible to ensure smooth operation. The smooth operation should at the same time ensure increased safety and better air, because the means of transport often do not stand in columns.

The conclusion of the article should deal with the description of how the proposed method should work. How it should guarantee the improvement of urban air while improving safety. Using the proposed method should ensure smooth operation and thus minimize the risks that lead to traffic accidents. Traffic accidents are evaluated annually. Fulfilment of vision 0 fails as planned. The proposed system should support this vision in order to achieve it.

\section{Current systems in practice for control of signals of light signalling equipment}

Technology development is moving very fast. This also leads to new systems, which are gradually trying to assert themselves in transport. The current offer on the market for the control of light signaling devices is currently sufficient. With current systems, it is possible to increase safety and ensure fluidity, while improving the city's air quality. [6], [7]

Current systems in practice are often referred to as dynamic systems. However, this designation can be understood as being largely limited by the distance or maximum range at which they work. We will now become more familiar with the offer on the market. [7], [8]

\subsection{Fixed signaling plane}

The fixed signaling device is the only representative of the static control of the light signaling device. 
From the point of view of developing technologies in a rocket-like way, however, the present time cannot replace this type of control. It can be stated that this would be an unnecessary process when this device has been operating in our country for many decades and is sufficient in many places.

\subsection{Variables signaling plane}

The function of variable signaling plans is based on defining the most popular times to increase the intervals at the places where constipation occurs. The most popular times can also be described as peak hours. Most often it is morning hours from 7 am to $8 \mathrm{pm}$ and afternoon from $2 \mathrm{pm}$ to $4 \mathrm{pm}$. These are intervals when we travel to work or take our children to school. Variable signaling plans can respond to these onslaughts based on predefined conditions by how much the green interval is extended.

\subsection{Video-detection}

Video detection is an element that makes it possible to dynamically control the intersection where light signaling devices are installed. It is currently the most modern dynamic system. Video-detection is very effective and with various settings, it is possible to create very effective control of intersections. The big disadvantage, which we consider to be very influencing the dynamics of the control, is the distance that the video-detector is limited. This is the distance that this system can work.

\subsection{Detekce pomocí indukčních smyček}

Induction loops are currently the most popular element used to control signals on light signaling devices. Certainly, we can classify them as dynamic elements. They open different directions or extend intervals as they pass. However, in heavy traffic, their dynamic control capability is limited by the distance from which they are installed. The big disadvantage of this signal is its implementation in the road. This causes considerable interference and limitations in case of its failure.

\section{Dynamic operation control design}

The proposed dynamic control of the intervals of the light signaling device can be realized with the help of the passage cameras on the points. These points can be described as entry roads to the city, where most automobile arrives and thus considerably congestion.

We call this place a control point and it is advisable to place it at a sufficient distance about the center of the city. On fig, 1 . We can see the data being worked on and a dynamic system can be created. [3],[4],[5] 


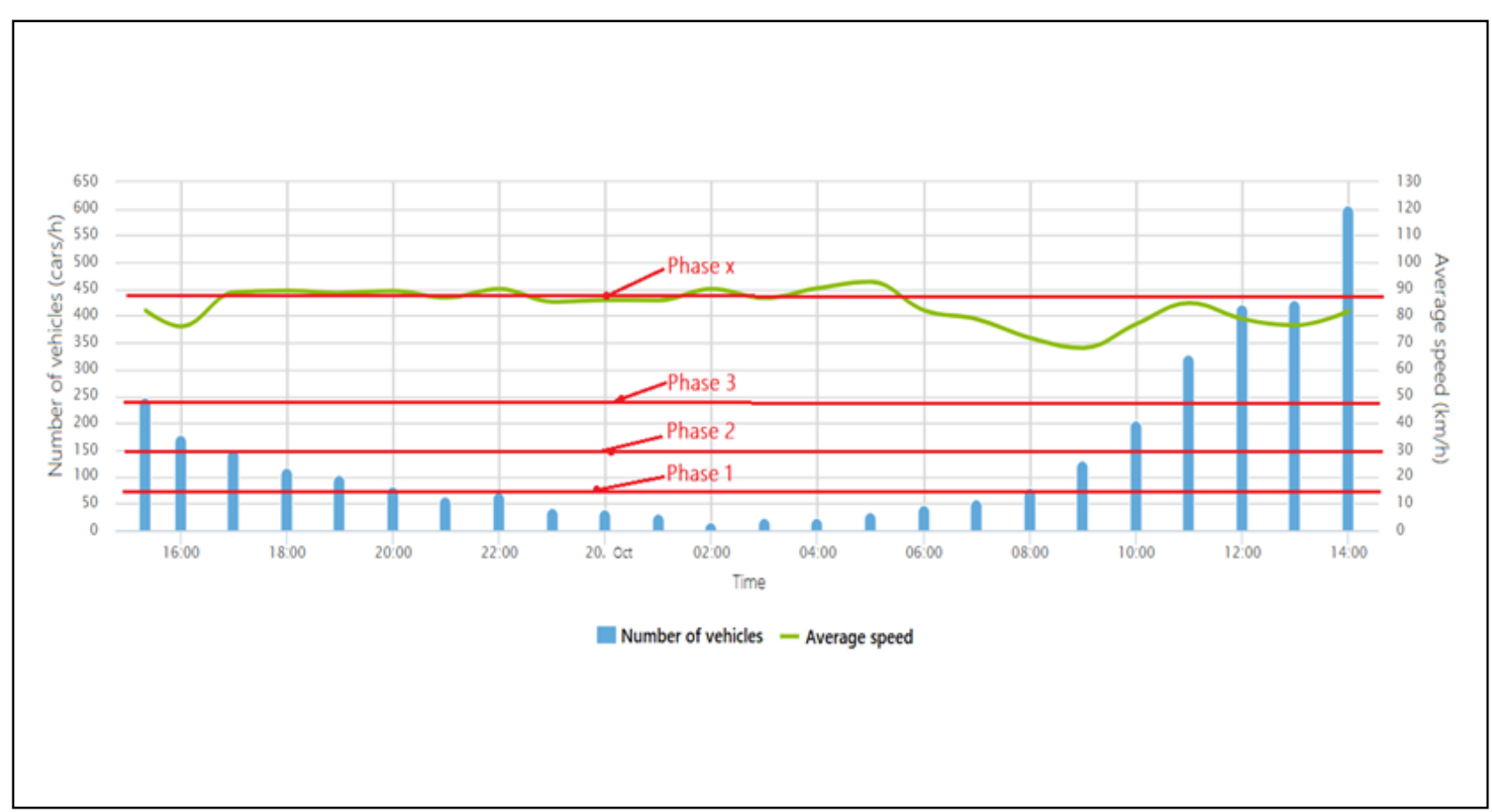

Fig. 1. Principle of management in individual phases.

In the picture, we can see several important data, w hich should create mathematical models for traffic management. The controls include the number of vehicles per hour and average speed. In the figure, we can see the marked phase 1 to phase $\mathrm{x}$. The phase-type may be more or less. The number of phases will depend on where the system is applied.

\subsection{Phase 1}

Phase 1 is referred to as an economically undemanding operation. It is a section where the traffic density is very low and the average speed on the monitored section is constant. At this time, the traffic lights are turned off. This situation occurs mostly on weekends holidays or evenings. These are intervals in which energy is saved because of the very low probability of a crisis situation.

\subsection{Phase 2}

In phase 2, the defined number of cars is exceeded and the light signaling devices are activated. This condition starts the traffic lights and at the same time sets the normal interval if the traffic density does not exceed Phase 3 in the monitored period.

\subsection{Phase 3}

The difference between Phase 2 and Phase 3 is only in the long signal "free" on the traffic light. If traffic density increases and exceeds from phase 2 to phase 3 , the off signal should be extended by 15 seconds. This time can be defined in advance and should be based on the number of lanes in a given direction and average speed. 


\subsection{Phase X}

Phase X presents us with a very extreme traffic density that occurs in the event of an obstacle and will thus significantly reduce the average speed in the monitored section. This phase may present a planned event, eg End of the concert in the next town, etc. This phase is currently only to present another possibility how to use the proposed method.

\section{Conclusion}

Nowadays it shows us that people without signal lights cannot function. Even a small outage causes considerable chaos on the roads. These situations create a very dangerous environment and incidents occur. The present company in the case of a longterm failure of the light signaling device should have a problem moving in its means of transport..

Traffic density increases every year. Pushing cars out of city centers is just a common solution. Based on such reactions, the cause is not solved, but the postponement is delayed until the time when the issue can overgrow and lead to fatal consequences.

We already have dynamic elements that work in real-time based on traffic density. The development of new intelligent systems can be observed every year. These systems help us but in order to dynamically control the operation it is necessary to work with the input data so that there is a robotic control based on artificial intelligence.

The proposed system works in real-time. Its advantage is working with data in recent hours and can free up crowded streets in city centers to make traffic smoother, safer and improve the air we breathe.

The next step should be testing the proposed method in real conditions. The proposed instrument should in future be able to operate, even after minor adjustments, in another transport sector, where it could significantly affect safety and fluidity.

\section{Acknowledgements}

This project is realized as the research with doctoral student and it is the basic input for next research, which we will develop in next term. It was realized with support of the university. This work was supported by Internal Grant Agency of Tomas Bata University under the project No. IGA/FAI/2019/010.

This work was supported by the research project VI20152019049 "RESILIENCE 2015: Dynamic Resilience Evaluation of Interrelated Critical Infrastructure Subsystems", supported by the Ministry of the Interior of the Czech Republic in the years 2015-2019. 
Mrazek, J.; Mrazkova, L.; Hromada, M. \& Vavra, J.: Traffic Control Through Traff...

\section{References}

Black, John. Urban transport planning: Theory and practice. Routledge, 2018.

Ehsani, Mehrsa; Ahmadi, Abbas; Fadai, Dawud. Modeling of vehicle fuel consumption and carbon dioxide emission in road transport. Renewable and sustainable energy reviews, 2016, 53: 1638-1648.

Garza-Reyes, J. A., Tangkeow, S., Kumar, V. and Nadeem, S. P. and NA (2018) Lean manufacturing adoption in the transport and logistics sector of Thailand - An exploratory study. Proceedings of the International Conference on Industrial Engineering and Operations Management Bandung, Indonesia, March 6-8, 2018, ID 45. pp. 104-115. ISSN 2169-8767 I. S. Jacobs and C. P. Bean, "Fine particles, thin films and exchange anisotropy," in Magnetism, vol. III, G. T. Rado and H. Suhl, Eds. New York: Academic, 1963, pp. 271-350.

Mrazek, Jan, Duricova, Lucia \& Hromada, Martin. „The Proposal of Software for Transport Infrastructure Management". In IISA 2017 - The 8th International Conference on Information, Intelligence, Systems and Applications, Larnaca, Cyprus, 28. 8. - 30. 8. 2017, ISBN 978-1-5090-342-1, 2017.

Mrazek, Jan, Duricova, Lucia \& Hromada, Martin. The Proposal of Evaluation Criteria for Recoverability of Road Transport. Safety and Reliability - Theory and Applications - Čepins \& Briš (Eds), 2017. Taylor \& Francis Group, London. ISBN 978-1-13862937-0.

Wang, Yi, et al. Dynamic traffic assignment: A review of the methodological advances for environmentally sustainable road transportation applications. Transportation Research Part B: Methodological, 2018, 111: 370-394.

Zhang, Ying. Method and system to dynamically collect statistics of traffic flows in a software-defined networking (sdn) system. U.S. Patent Application No 14/462,444, 2016.

Zhang, Linfeng, et al. Deep potential molecular dynamics: a scalable model with the accuracy of quantum mechanics. Physical review letters, 2018, 120.14: 143001. 